\title{
Ultrasound-Guided Aspiration Biopsy for Detection of Nonpalpable Axillary Node Metastases in Breast Cancer Patients: New Diagnostic Method
}

\author{
Jorien Bonnema, M.D., ${ }^{1}$ Albert N. van Geel, M.D., Ph.D., ${ }^{1}$ Bart van Ooijen, M.D., Ph.D., ${ }^{1}$ \\ Sybrand P.M. Mali, M.D., ${ }^{2}$ Swanny L. Tjiam, M.D., ${ }^{2}$ Sonja C. Henzen-Logmans, M.D., ${ }^{3}$ \\ Paul I.M. Schmitz, Ph.D., M.Sc., ${ }^{4}$ Theo Wiggers, M.D., Ph.D. ${ }^{1}$ \\ ${ }^{1}$ Department of Surgical Oncology, University Hospital/Daniel den Hoed Cancer Center, Zuider Hospital, Groene Hilledijk 301,3075 EA \\ Rotterdam, The Netherlands \\ ${ }^{2}$ Department of Radiology, University Hospital Rotterdam/Daniel den Hoed Cancer Center, Groene Hilledijk 301, 3075 EA Rotterdam, The \\ Netherlands \\ ${ }^{3}$ Department of Pathology, University Hospital Rotterdam/Daniel den Hoed Cancer Center, Groene Hilledijk 301, 3075 EA Rotterdam, The \\ Netherlands \\ ${ }^{4}$ Department of Statistics, University Hospital Rotterdam/Daniel den Hoed Cancer Center, Groene Hilledijk 301, 3075 EA Rotterdam, The \\ Netherlands
}

\begin{abstract}
This study was designed to evaluate the accuracy of ultrasonography alone and in combination with fine-needle aspiration biopsy (FNAB) for detection of axillary metastases of nonpalpable lymph nodes in breast cancer patients. Ultrasonography was carried out in 150 axillas of 148 patients (mean age 57 years, range $30-80$ years); and in 93 axillas lymph nodes were detected. Nodes were described according to their dimension and echo patterns and were compared with histopathologic results. FNAB was carried out in 81 axillas (122 nodes). The sensitivity of ultrasonography was highest $(87 \%)$ when size (length $>5 \mathrm{~mm}$ ) was used as criterion for malignancy, but the specificity was rather low $(56 \%)$. When nodes with a malignant pattern (echo-poor or inhomogeneous) were visualized, specificity was $\mathbf{9 5 \%}$. Ultrasound-guided FNAB had a sensitivity of $\mathbf{8 0 \%}$ and a specificity of $\mathbf{1 0 0 \%}$ and detected metastases in 63\% of node-positive patients. It is concluded that FNAB is an easy, reliable, inexpensive method for identifying patients with positive nodes. In the case of negative findings, other diagnostic procedures to exclude lymph node metastases, such as sentinel node mapping, could be performed.
\end{abstract}

In breast cancer patients the number and level of axillary lymph node metastases are important prognostic indicators and determinants for selecting patients who should receive adjuvant treatment [1]. Complete axillary dissection with histologic examination of nodes provides the most accurate information about nodal status [2-4]. However, node-negative patients who are not selected for adjuvant treatment probably do not benefit by this procedure, which causes morbidity [5] and prolongs hospital stay [6]. Efforts have been made to avoid complete axillary dissection by preoperative evaluation with imaging techniques [7] or intraoperative assessment by axillary node sampling [8].

Ultrasonography has been used as an imaging method to detect axillary nodes of breast cancer patients in several studies [9-13]. Patients with and without clinically positive nodes were included

Correspondence to: A.N. van Geel, M.D., Ph.D. in these studies, and ultrasonographic enlargement of a node was used as the only criterion for malignancy. The results may differ for patients with clinically negative nodes, and nodal size alone is reported to be of limited value for ultrasonographic differentiation between benign and malignant disease [14]. Better results can be obtained with high resolution ultrasonography using ultrasonomorphologic features as criteria for malignancy [14]. Combining ultrasonography with fine-needle aspiration biopsy (FNAB) may further improve the presurgical staging of the axilla in breast cancer patients [15].

The purpose of this prospective study was to assess the accuracy of ultrasonography (using ultrasonomorphologic criteria for malignancy) and of ultrasound-guided FNAB for detection of axillary lymph node metastases in breast cancer patients without palpable nodes at clinical examination.

\section{Methods}

During a 15-month period all patients with proved breast cancer without palpable axillary nodes and amenable to axillary dissection were included in the study. The absence of clinically enlarged nodes was confirmed by two experienced clinicians. Excluded were patients who underwent preoperative radiotherapy or chemotherapy. The day before surgery ultrasound examination of the ipsilateral axilla was carried out by two experienced radiologists using a $7.5 \mathrm{MHz}$ linear array transducer (Acuson 128). The area between the axillary vein, latissimus dorsi muscle, and medial border of the pectoralis minor muscle was carefully inspected. Any definable mass within the axilla was considered to be a lymph node.

The echo patterns of axillas without visible nodes and axillas with nodes with an echo-rich or homogeneous aspect, so called benign characteristics $[14,16]$, were considered not suspect for 
malignancy. Echo-poor and inhomogeneous nodes were considered suspect for metastatic deposit $[14,16]$. The length of the node, defined as the largest diameter on ultrasonography (US) in millimeters, was scored. An ultrasound-guided FNAB was obtained with a 21-gauge needle from at least one visible node, regardless of the echo pattern, with a maximum of four biopsies per axilla. The aspirated node was marked by leaving $0.5 \mathrm{~cm}$ of a guidewire to make a comparison with histologic findings possible. The aspiration biopsies were analyzed for cytologic features and classified as benign or malignant. After FNAB all patients underwent complete axillary dissection and resection of the primary tumor either by segmental or total mastectomy. The standard anatomic borders of the axillary dissection were the axillary vein, latissimus dorsi muscle, medial border of the pectoralis minor muscle, serratus anterior muscle, and subscapular muscle. Level I, II, and III nodes were resected. The specimen was examined by radiology and the marked nodes were indicated with needles for easy localization by the pathologist. All axillary specimens were processed for histologic examination using hematoxylin and eosin $(\mathrm{H} \& \mathrm{E})$ and examined by the pathologist.

The results were analyzed with descriptive statistical methods. Sensitivity, specificity, overall accuracy, and positive and negative predictive values were calculated by comparing the results of ultrasonography and FNAB with histologic findings, according to the following matrix.

\begin{tabular}{lcc}
\hline & \multicolumn{2}{c}{ Histology } \\
\cline { 2 - 3 } & Positive & Negative \\
\hline Examination method & $\mathrm{A}$ & $\mathrm{B}$ \\
Positive & $\mathrm{C}$ & $\mathrm{D}$ \\
Negative & & \\
\hline
\end{tabular}

Sensitivity: A/A + C; specificity: D/D + B; overall accuracy: A + D/A $+\mathrm{B}+\mathrm{C}+\mathrm{D}$; positive predictive value: $\mathrm{A} / \mathrm{A}+\mathrm{B}$; negative predictive value: $\mathrm{D} / \mathrm{D}+\mathrm{C}$.

\section{Results}

Ultrasonography was performed in 150 axillas of 148 patients. Two patients with synchronous bilateral breast cancer underwent bilateral examination and axillary dissection. The age range was 30 to 80 years (mean 57 years). The histology of the primary tumor was invasive ductal carcinoma in 135 patients $(91 \%)$, invasive lobular carcinoma in 6 patients $(4 \%)$, and other histologic types of breast cancer in 7 patients. There were $78 \mathrm{~T} 1$ tumors (51\%), 66 T2 tumors $(43 \%)$, and 6 T3 tumors $(6 \%)$. The mean number of nodes in the axillary specimen was 14 (range 4-32). Lymph node metastases were present in 62 axillas (41\%), 40 of these having fewer than four positive nodes (26 axillas one node, 7 two nodes, 7 three nodes), 22 axillas having four or more positive nodes. The ultrasound examination detected axillary nodes in 93 axillas (62\%); no nodes could be detected in 57 axillas $(38 \%)$. A total of 143 nodes could be visualized, of which 122 were aspirated. In 47 axillas one, in 29 axillas two, in 3 axillas three, and in 2 axillas four successful biopsies were performed. In 12 axillas with 21 visualized nodes FNAB was not possible because the position of the node was too difficult, the node was too small, or no adequate material could be obtained. The mean length of the nodes was $14 \mathrm{~mm}$ (range 6-25 $\mathrm{mm}$ ).

The results of ultrasonography, cytology, and histology of the
Table 1. Ultrasonography and cytologic and histologic results.

\begin{tabular}{|c|c|c|c|c|c|}
\hline Echo pattern & $\begin{array}{l}\text { No } \\
\text { cytology }\end{array}$ & $\begin{array}{l}\text { Benign } \\
\text { cytology }\end{array}$ & $\begin{array}{l}\text { Malignant } \\
\text { cytology }\end{array}$ & $\begin{array}{l}\text { Total } \\
\text { no. }\end{array}$ & $\begin{array}{l}\text { Malignant } \\
\text { histology }\end{array}$ \\
\hline \multicolumn{6}{|l|}{ Benign } \\
\hline Target & 9 & 39 & 10 & 58 & 25 \\
\hline Homogeneous & 2 & 10 & 18 & 30 & 21 \\
\hline \multicolumn{6}{|l|}{ Malignant } \\
\hline Hypoechogenic & 7 & 6 & 16 & 29 & 25 \\
\hline Inhomogeneous & 0 & 3 & 4 & 7 & 6 \\
\hline No classification & 3 & 7 & 9 & 19 & 14 \\
\hline Total & 21 & 65 & 57 & 143 & 91 \\
\hline
\end{tabular}

Table 2. Ultrasonography and FNAB of axillary nodes.

\begin{tabular}{|c|c|c|c|}
\hline \multirow[b]{2}{*}{ Parameter $(\%)$} & \multicolumn{2}{|c|}{$\begin{array}{l}\text { Ultrasonography, by } \\
\text { criterion for malignancy }\end{array}$} & \multirow[b]{2}{*}{ FNAB } \\
\hline & $\begin{array}{l}\text { Echo pattern } \\
\text { of node }\end{array}$ & $\begin{array}{l}\text { Node size } \\
>5 \mathrm{~mm}\end{array}$ & \\
\hline Sensitivity & 36 & 87 & 80 \\
\hline Specificity & 95 & 56 & 100 \\
\hline Overall accuracy & 67 & 68 & 88 \\
\hline Positive predictive value & 86 & 58 & 100 \\
\hline Negative predictive value & 63 & 86 & 76 \\
\hline
\end{tabular}

lymph nodes are summarized in Table 1 . The aspects of the lymph nodes detected by ultrasonography were categorized as not suspect for malignancy, suspect for malignancy, or no classification possible, as described above, and compared with the gold standard: the results of the histologic examination. The sensitivity was $36 \%$, specificity $95 \%$, overall accuracy $67 \%$, positive predictive value $86 \%$, and negative predictive value $63 \%$ (Table 2 ).

In previous studies all axillary nodes visualized with ultrasonography [10-12] or nodes with a diameter of at least $5 \mathrm{~mm}$ [9] were considered as involved with metastasis. The diameter of the smallest node detected in our study was $6 \mathrm{~mm}$. When any visible node was defined as malignant, sensitivity was $87 \%$, specificity $56 \%$, overall accuracy $68 \%$, and positive and negative predictive values $58 \%$ and $86 \%$, respectively (Table 2 ).

The results of FNAB versus histologic outcome are summarized in Figure 1. Positive cytologic analysis (one or more nodes positive) was found in 39 axillas. All the positive cytologies were confirmed to be metastatic by light microscopic examination. Of the cytologic negative axillas, 10 of $42(24 \%)$ were positive for malignancy with histologic examination. The number of positive nodes per axilla clearly influenced the chance of detection: only 11 of 26 axillas with one positive node were detected by FNAB, in contrast to 19 of 22 axillas with four or more positive nodes. It was possible to detect $39(63 \%)$ of the 62 positive axillas in $26 \%$ of the total patient population. The sensitivity of FNAB was $80 \%$, the specificity $100 \%$, the overall accuracy $88 \%$, and the positive and negative predictive values $100 \%$ and $76 \%$, respectively (Table 2).

\section{Discussion}

Axillary dissection has a central place in breast cancer treatment, although debate exists about the extent of dissection necessary for adequate staging [17]. Complete axillary dissection can be considered overtreatment for those patients whose nodes do not contain 


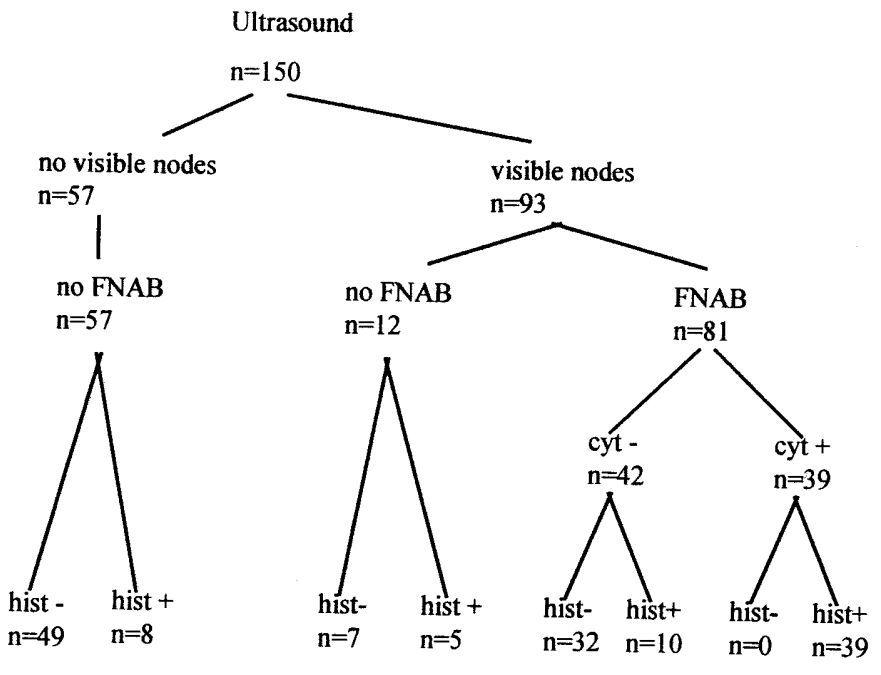

Fig. 1. FNAB and cytologic and histologic results. $\mathrm{n}=$ number of axillas; cyt-: cytologic outcome benign; cyt + : cytologic outcome malignant; hist-: histologic outcome benign; hist + : histologic outcome malignant.

metastases with histologic examination [18]. Most of these patients have T1 and T2 tumors, as it is well established that the incidence of lymph node involvement increases with increasing diameter of the tumor [19]. This correlation is already seen for small (T1) tumors [18]. In our study T1 and T2 tumors were found in $94 \%$ of the patients, and lymph node metastases were present in $41 \%$. As the number of patients presenting with early stage breast cancer without axillary metastases will increase as a result of breast screening activities, the need to look for alternatives for axillary dissection becomes more compelling [20]. The use of neoadjuvant chemotherapy necessitates alternative techniques for assessment of metastatic status of axillary nodes [21]: first to select patients with positive nodes and second because of a lack of histopathologic control of treatment results during chemotherapy.

Clinical examination for assessment of axillary metastases is notoriously unreliable, with an overall error rate of $39 \%$ and a false-negative rate up to $45 \%$ [22]. No imaging technique until now has been successful enough to replace the histologic examination. One should realize that it will be almost impossible to reach a sensitivity higher than $90 \%$ with any imaging technique because occult micrometastases are found in at least $9 \%$ of patients [23]. The results of radionuclide lymphography [24] or immunoscintigraphy [25] do not differ from those of the clinical examination. CT scans and MRI are limited to diagnosing enlargement of lymph nodes without being able to differentiate between those infiltrated with cancer from hyperplastic glands [26, 27]. Other drawbacks of CT and MRI are the high cost and the difficulty of obtaining material for pathologic analysis. New techniques such as positron emission tomography are even costlier than CT and MRI, and experiences with this method are limited [28]. Ultrasonography, a frequently used technique for lymph node imaging, is characterized by low cost and the possibility of obtaining biopsy specimens. Several studies have shown that ultrasonography has value for the detection of enlarged lymph nodes in breast cancer [9-13], head and neck cancer [29-31], and gastrointestinal cancer [32]. For the detection of axillary node metastases in breast cancer the sensitivity and the specificity varied between $56 \%$ and $72 \%$ and $70 \%$ and $90 \%$, respectively [9-13]. A problem is, as in the case of CT and MRI, the differentiation between benign and malignant nodes. Nodal size has been tested for validity as a criterion for malignancy. For cervical nodes the minimal axial diameter $(2-30 \mathrm{~mm})$ was the most accurate parameter to use for predicting tumor-positive nodes [31]. Nodal size varies among the regions in the body, and size criteria for malignancy of lymph nodes in the axilla are not known. We detected nodes only with a longitudinal diameter of 6 $\mathrm{mm}$ or more. If enlargement was used as the only criterion for malignancy, the sensitivity of ultrasonography was $87 \%$ and the specificity only $56 \%$.

High-resolution ultrasonography enables differentiation between benign and malignant echo pattern characteristics [14]. Nodes with an echo-rich center are expected to be benign, and nodes with an echo-poor center or inhomogeneous architecture are more suspect for tumor infiltration $[14,16,33]$. We used this technique in our study. Sensitivity was low $(36 \%)$ and specificity high $(95 \%)$, which means that ultrasonography of axillary nodes is more accurate for the diagnosis of metastatic than nonmetastatic lymph nodes. However, the accuracy of ultrasonography is too low to rely on this technique for selection of node-negative or node-positive patients. Therefore we combined ultrasonography with FNAB of visualized nodes. The latter is a reliable method for diagnosing primary carcinoma of the breast [34]. In our study, FNAB could not improve the sensitivity of ultrasonography alone, because of a false-negative rate of $12 \%$. Analysis of the falsenegative findings showed that 7 of the 10 false-negative axillas contained only one metastatic node, which makes it more difficult to aspirate the right node. Ultrasound-guided FNAB therefore cannot be used to select patients with negative nodes in whom an axillary dissection can be omitted for this reason. The specificity of the technique, however, was $100 \%$, as there were no cases of positive cytology that proved to be negative on histology. In our study population of 148 patients with 62 node positive axillas, 39 of these patients $(63 \%)$ could be accurately detected by ultrasound-guided FNAB. The high specificity makes the technique valuable for staging patients entering neoadjuvant chemotherapy protocols and others who are not selected for surgery as primary treatment.

Experiments with sentinel node resection have also successfully identified node-positive breast cancer patients [35, 36]. Although the technique is more conservative than axillary dissection, surgical resection of the sentinel node with some form of anesthesia is still needed. Ultrasound-guided FNAB is minimally invasive, needs no anesthesia, and is easier to perform than the sentinel node biopsy. It can detect $63 \%$ of positive axillas in patients with small breast tumors. In our opinion, the sequence of diagnostic procedures in the future to detect axillary node metastases could be to perform first FNAB and, in case of negative findings, a sentinel node biopsy. The technical ease of the procedures and the major reduction in morbidity and costs that can be expected justify larger clinical trials to verify the feasibility and accuracy of these new diagnostic methods.

In conclusion, ultrasound-guided FNAB has a high sensitivity and specificity for detecting axillary lymph node metastases in patients with $\mathrm{T} 1$ and $\mathrm{T} 2$ tumors. In this study $63 \%$ of nodepositive patients could be identified as having metastases. In these patients other, more invasive diagnostic methods can be avoided. 


\section{Résumé}

Le but de cette étude a été d'évaluer la précision de l'échographie seule ou associée à la ponction biopsique à l'aiguille (PBA) pour détecter des métastases axillaires des ganglions lymphatiques non-palpables chez la femme ayant un cancer du sein. On a examiné en échographie 150 aisselles chez 148 femmes (âge moyen 57 ans; extrêmes 30-80 ans); on a ainsi détecté 93 ganglions. Les ganglions ont été analysés selon leur dimensions et leur caractères échogéniques et ces résultats ont été comparés aux données de l'examen anatomopathologique. Cent vingt-deux ganglions ont fait l'objet de PBA (81 creux axillaires). La sensibilité de l'échographie a été la meilleure $(87 \%)$ lorsque l'on a pris la taille $(>5 \mathrm{~mm})$ comme critère de malignité, alors que pour ce même critère, la spécificité a été relativement basse (56\%). En prenant comme critère les caractères échogéniques (visualisation difficile ou hétérogène), la spécificité a été de 95\%. La PBA échoguidée avait une sensibilité de $80 \%$ et une spécificité de $100 \%$; elle a détecté des métastases chez $63 \%$ des patientes ayant des ganglions positifs. On conclue que la PBA est une méthode facile, fidèle et peu coûteuse pour identifier les patients ayant des ganglions positifs. En cas d'examen négatif, on pourrait alors envisager d'autres investigations telles que la cartographie des adénopathies sentinelles.

\section{Resumen}

El presente estudio fue diseñado para evaluar la precisión de la ultrasonografía sola o en combinación con aspiración con aguja fina (AAF) en la detección de metástasis axilares en ganglios linfáticos no palpables en pacientes con cáncer mamario. Se practicó ultrasonografía en 150 axilas de 148 pacientes (edad promedio de 57 años, rango 30-80 años) y en 93 axilas se detectaron ganglios. Los ganglios fueron descritos de acuerdo con su dimensión y patrón ecogénico, para comparación con los resultados histopatológicos. En 81 axilas (122 ganglios) se practicó AAF. La sensibilidad de la ultrasonografía fue máxima $(87 \%)$ cuando el tamaño (longitud $>5 \mathrm{~mm}$ ) fue utilizado como criterio de malignidad, pero la especificidad fue más bien baja $(56 \%)$. Cuando se visualizaron ganglios con patrón de malignidad (ecogenicidad pobre o poca homogeneidad), la especificidad fue $95 \%$. La AAF guiada por ultrasonografía tuvo una sensibilidad de $80 \%$ y una especificidad de $100 \%$ y detectó metástasis en $63 \%$ de las pacientes con ganglios positivos. Se concluye que la AAF es un método fácil, confiable y de bajo costo para identificar pacientes con ganglios positivos. En el caso de hallazgos negativos, se pueden practicar otros procedimientos diagnósticos para excluir metástasis ganglionares, tales como mapeo de ganglios centinela.

\section{References}

1. Fisher, B., Bauer, M., Wickerham, D., Redmond, C.K., Fisher, E.R.: Relation of number of positive axillary nodes to the prognosis of patients with primary breast cancer: an NSABP update. Cancer 52:1551, 1983

2. Fentiman, I.S., Mansel, R.E.: The axilla: not a no-go zone. Lancet 337:221, 1991

3. Axelsson, C.K., Moudridsen, H.T., Zedeler, K.: Axillary dissection of level I and II lymph nodes is important in breast cancer classification. Eur. J. Cancer 28A:1415, 1992

4. Senofsky, G.M., Moffat, F.L., Davis, K., Masri, M.M., Clark, K., Robinson, D.S., Sabates, B., Ketcham, A.S.: Total axillary lymphade- nectomy in the management of breast cancer. Arch. Surg. 126:1336, 1991

5. Recht, A., Houlihan, M.J.: Axillary lymph nodes and breast cancer. Cancer 76:1491, 1995

6. Ivens, D., Hoe, A.L., Podd, T.J., Hamilton, C.R., Taylor, I., Royle, G.T.: Assessment of morbidity from complete axillary dissection. Br. J. Cancer 66:136, 1992

7. Maisey, M.N.: Imaging techniques in breast cancer: What is new? What is useful?-a review. Eur. J. Cancer Clin. Oncol. 24:61, 1988

8. Hadiminas, D.J., Burke, M.: Intraoperative assessment of nodal status in the selection of patients with breast cancer for axillary clearance. Br. J. Surg. 81:1615, 1994

9. Bruneton, J.N., Caramella, E., Hery, M., Aubanel, D., Manzino, J.J., Picard, J.L.: Axillary lymph node metastases in breast cancer: preoperative detection with ultrasound. Radiology 158:325, 1986

10. Mustonen, P., Farin, P., Kosunen, O.: Ultrasonographic detection of metastatic axillary lymph nodes in breast cancer. Ann. Chir. Gynaecol. 79:15, 1990

11. Tate, J.J.T., Lewis, V., Archer, T., Guyer, P.G., Royle, G.T., Taylor, I.: Ultrasound detection of axillary lymph node metastases in breast cancer. Eur. J. Surg. Oncol. 15:139, 1989

12. De Freitas, R., Jr., Costa, M.V., Schneider, S.V., Nicolau, M.A., Marussi, E.: Accuracy of ultrasound and clinical examination in the diagnosis of axillary lymph node metastases in breast cancer. Eur. J. Surg. Oncol. 17:240, 1991

13. Pamilo, M., Soiva, M., Lavast, E.M.: Real-time ultrasound, axillary mammography, and clinical examination in the detection of axillary lymph node metastases in breast cancer patients. J. Ultrasound Med. $8: 115,1989$

14. Vassallo, P., Wernecke, K., Roos, N., Peters, P.E.: Differentiation between benign from malignant superficial lymphadenopathy: the role of high resolution US. Radiology 183:215, 1992

15. Ceci, G., Pescarenico, M.G., Di Sarra, S., Manotti, L., Cocconi, G.: Ultrasound (US) examination of axillary nodes with fine needle aspiration biopsy (FNAB): a new non invasive diagnostic method improving the presurgical staging of breast carcinoma [abstract]. Proc. Am. Soc. Clin. Oncol. 14:109, 1995

16. Sakai, F., Kyono, K., Sone, S., Kondo, Y., Oguchi, M., Watanabe, T., Sakay, Y., Imay, Y., Takeda, S., Yamamoto, K.: Ultrasonic evaluation of cervical metastatic lymphadenopathy. J Ultrasound Med. 7:305, 1988

17. Greenall, M.J., Davidson, T.: How should the axilla be treated in breast cancer? Eur. J. Surg. Oncol. 21:2, 1995

18. Silverstein, M.J., Glerson, E.D., Waisman, J.R., Senotsky, G.M., Colburn, W.J., Gamagani, P.: Axillary lymph node dissection for T1a breast carcinoma: is it indicated? Cancer 73:664, 1994

19. Hartveit, F.: Axillary metastasis in breast cancer: when, how, and why? Semin. Surg. Oncol. 5:126, 1989

20. Walls, J., Boggis, C.R.M., Wilson, M., Asbury, D.L., Roberts, J.V., Bundred, N.J., Mansel, R.E.: Treatment of the axilla in patients with screen-detected breast cancer. Br. J. Surg. 80:436, 1993

21. Belembaogo, E., Feillel, V., Chollet, P., Cure, H., Verrelle, P., Kwiatkowski, F., Achard, J.L., Le Bouedec, G., Chassagne, J., Bignon, Y.J., de Latour, M., Lafaye, C., Dauplat, J.: Neoadjuvant chemotherapy in 126 operable breast cancers. Eur. J. Cancer 28A:896, 1992

22. Sacre, R.A.: Clinical evaluation of axillary lymph nodes compared to surgical and pathological findings. Eur. J. Surg. Oncol. 12:169, 1986

23. International (Ludwig) Breast Cancer Study Group: Prognostic importance of occult axillary lymph node micrometastases from breast cancers. Lancet 335:1565, 1990

24. McClean, R.G., Ege, G.N.: Prognostic value of axillary lymphoscintigraphy in breast carcinoma patients. J. Nucl. Med. 27:1116, 1986

25. Tjandra, J.J., Sacks, N.P.M., Thompson, C.H., Leyden, M.J., Stacker, S.A., Lichtenstein, M., Russell, I.S., Collins, J.P., Andrews, J.T., Pietersz, G.A., McKenzie, I.F.C.: The detection of axillary lymph node metastases from breast cancer by radiolabelled monoclonal antibodies: a prospective study. Br. J. Cancer 59:296, 1989

26. Meyer, J.E., Munzenrider, J.E.: Computer tomographic demonstration of lymph node metastases in patients with recurrent breast cancer. Radiology 139:661, 1991

27. Allan, S.M., McVicar, D., Sacks, N.P.M. Prospects for axillary staging in breast cancer by magnetic resonance imaging [abstract]. Br. J. Radiol. 66(Suppl.):15, 1993 
28. Adler, L.P., Crowe, J.P., Al-Kaisi, N.K., Sunshine, J.L.: Evaluation of breast masses and axillary lymph nodes with [F-18] 2-deoxy-2-fluoroD-glucose PET. Radiology 187:743, 1993

29. Sutton, R.T., Reading, C.C., Charboneau, J.W., James, E.M., Grant, C.S., Hay, I.D.: US-guided biopsy of neck masses in post-operative management of patients with thyroid cancer. Radiology 168:769, 1988

30. Bruneton, J.N., Roux, P., Caramello, E., Demard, F., Vallicioni, J., Chauvel, P.: Ear, nose and throat cancer: ultrasound diagnosis of metastatis to cervical lymph nodes. Radiology 152:771, 1984

31. Van den Brekel, M.W.M., Castelijns, J.A., Snow, B.: Detection of lymph node metastases in the neck: radiologic criteria. Radiology 192:617, 1994

32. Lok Tio, T., Coene, P.P.L.O., Schouwink, M.H., Tijtgat, G.N.: Esophagogastric carcinoma: preoperative TNM classification with endosonography. Radiology 173:411, 1989

\section{Invited Commentary}

\author{
Alastair R. Brown, M.D. \\ Royal North Shore Hospital, Sydney, Australia
}

This report by Bonnema et al. describes a well conducted study that has demonstrated that the addition of FNAB to the use of ultrasound for examining axillary lymph nodes in breast cancer patients can significantly enhance the specificity of the examination. Although it also improves the sensitivity, there is unfortunately a significant margin of error in relation to the negative results. Of the 150 axillas examined, 39 were positive by this technique, and all were confirmed to be histologically positive. However, a further 23 axillas were also found to be histologically positive, but of these 8 had no visible nodes on ultrasound scans and 5 were not able to have FNAB done; the other 10 had FNAB done, but the cytology was negative.

In current practice, axillary lymph node dissection has a diagnostic as well as a therapeutic function. The diagnosis of axillary lymph node involvement is the most important prognostic indicator in breast cancer, and an adequate axillary dissection, as part of the primary treatment, is considered by many authorities to confer a positive therapeutic advantage in patients with involved nodes. However, axillary dissection is associated with significant longterm, as well as short-term, morbidity. Such morbidity is always undesirable, but it is even less tolerable for patients whose nodes
33. Kruyt, R.H., van Putten, W.L.J., Levendag, P.C., de Boer, M.F., Oudkerk, M.: Biopsy of nonpalpable cervical lymph nodes: are selection criteria for ultrasound guided biopsy in patients with head and neck small cell carcinoma justifiable? Ultrasound Med. Biol. 22:413, 1996

34. Patell, J.J., Gartell, P.C., Smallwood, J.A., Herbert, A., Royle, G., Buchanan, R., Taylor, I.: Fine needle aspiration cytology of breast masses: an evaluation of its accuracy and reasons for diagnostic failure. Ann R. Coll. Surg. Engl. 69:156, 1987

35. Krag, D.N., Weaver, D.L., Alex, J.C., Fairbank, J.T.: Surgical resection and radiolocalization of the sentinel lymph node in breast cancer using a gamma probe. Surg. Oncol. 2:335, 1993

36. Giuliano, A.E., Kirgan, D.M., Guenther, J.M., Morton, D.L.: Lymphatic mapping and sentinel lymphadenectomy for breast cancer. Ann. Surg. 220:391, 1994

prove to be clear. If therefore a reliable noninvasive diagnostic technique could be developed for identifying the patients who need a therapeutic axillary dissection and those who do not (i.e., which patients have involved nodes and which do not) without having to perform a diagnostic axillary dissection, it would have the potential for widespread application. Unfortunately, with its present level of sensitivity, this technique cannot yet fill that role.

If neoadjuvant systemic therapy, hormonal or chemotherapeutic, were to be given to all patients regardless of their lymph node status, it could be argued from the point of view of locoregional control that axillary dissection could be deferred, and blind adjuvant radiotherapy to the axilla also withheld until such time as involvement of the nodes was confirmed-as is usually done with skin malignancies. Under such circumstances the use of US with FNAB would be a useful part of such imaging surveillance. However, at the present time few clinicians (or patients) are able to accept a "wait and see" plan of management for the axilla in the presence of invasive cancer of the breast. It would require a controlled clinical trial, therefore, to determine whether such a plan of management could be recommended.

For the present, the technique seems to have a limited diagnostic role, because it cannot yet be relied on for making such important therapeutic decisions as whether to dissect the axilla. Nevertheless, it is a technique worth developing, and we look forward to reading more reports of experience with its use and, it is hoped, a controlled clinical trial of its application in a therapeutic setting. 